\title{
Lipopolysaccharide preconditioning enhances the efficacy of mesenchymal stem cells transplantation in a rat model of acute myocardial infarction
}

\author{
Yongwei Yao', Fumin Zhang*1, Liansheng Wang1, Guohui Zhang², \\ Zhaojun Wang ${ }^{1}$, Jianmei Chen ${ }^{1}$ and Xiang Gao ${ }^{3}$
}

Address: ${ }^{1}$ Department of Cardiology, First Affiliated Hospital of Nanjing Medical University, 300 Guangzhou Road, Nanjing 210029, PR China, ${ }^{2}$ Department of Cardiology, The Affiliated Zhengjiang First People's Hospital of Jiangsu University, 8 Dianli Road, Zhengjiang 212000, PR China and ${ }^{3}$ Model Animal Research Center, Nanjing University, 12 Xuefu Road, Pu Kou district, Nanjing 210061, PR China

Email: Yongwei Yao - ywyao78@sina.com.cn; Fumin Zhang* - fminzhang@sohu.com; Liansheng Wang - drlswang@njmu.edu.cn; Guohui Zhang - laoyao_1978@sina.com.cn; Zhaojun Wang - doctorwangzj@yahoo.com.cn; Jianmei Chen - chenjianmei88@sina.com;

Xiang Gao - gaox@nicemice.cn

* Corresponding author

Published: 20 August 2009

Journal of Biomedical Science 2009, 16:74 doi:10.1/86/1423-0I27-16-74

This article is available from: http://www.jbiomedsci.com/content//6/1/74

(c) 2009 Yao et al; licensee BioMed Central Ltd.

This is an Open Access article distributed under the terms of the Creative Commons Attribution License (http://creativecommons.org/licenses/by/2.0), which permits unrestricted use, distribution, and reproduction in any medium, provided the original work is properly cited.
Received: 8 June 2009

Accepted: 20 August 2009

\begin{abstract}
Background: Mesenchymal stem cells (MSCs)-based regenerative therapy is currently regarded as an alternative approach to salvage the acute myocardial infarcted hearts. However, the efficiency of MSCs transplantation is limited by lower survival rate of engrafted MSCs. In previous study, we found that $1.0 \mu \mathrm{g} / \mathrm{ml}$ Lipopolysaccharide (LPS) could protect MSCs against apoptosis induced by oxidative stress and meanwhile enhance the proliferation of MSCs. Therefore, in the present study, we firstly preconditioned MSCs with $1.0 \mu \mathrm{g} / \mathrm{ml}$ LPS, then transplanted MSCs into ischemic myocardium, and observed the survival and cardiac protective capacity of MSCs in a rat model of acute myocardial infarction. Furthermore, we tried to explore the underlying mechanisms and the role of Toll-like receptor-4 (TLR4) in the signal pathway of LPS-induced cardiac protection.
\end{abstract}

Methods and results: Acute myocardial infarction model was developed by left anterior descending coronary artery ligation. 60 rats were divided into 4 groups randomly and given an intramyocardial injection of one of the following treatments: $30 \mu \mathrm{l} \mathrm{PBS} \mathrm{(control} \mathrm{group),} 3 \times 10^{6}$ wild MSCs/30 $\mu \mathrm{l}$ (wMSCs group), $3 \times 10^{6}$ LPS-preconditioned wild MSCs/30 $\mu \mathrm{l}$ (LPS-wMSCs group), or $3 \times 10^{6}$ LPS-preconditioned TLR4 gene deleted MSCs/30 $\mu$ (LPS-tMSCs group). After 3 weeks, LPS-preconditioned wild MSCs transplantation ameliorated cardiac function and reduced fibrosis of infarcted myocardium. Vascular density was markedly increased in LPS-wMSCs group compared with other three groups. Survival rate of engrafted MSCs was elevated and apoptosis of myocardium was reduced in infarcted heart. Expression of vascular endothelial growth factor (VEGF) and phospho-Akt was increased in the infarcted myocardium after transplantation of LPSpreconditioned MSCs.

Conclusion: LPS preconditioning enhanced survival of engrafted MSCs, stimulated expression of VEGF and activated PI3K/Akt pathway. LPS preconditioning before MSCs transplantation resulted in superior therapeutic neovascularization and recovery of cardiac function. LPS preconditioning provided a novel strategy in maximizing biologic and functional properties of MSCs. 


\section{Background}

Despite the clinical success of reperfusion therapy, a large proportion of patients develop myocardial necrosis, ventricular remodelling and resultant congestive heart failure after acute myocardial infarction (AMI) [1]. Mesenchymal stem cells (MSCs)-based regenerative therapy is currently regarded as an alternative approach to salvage the MI hearts [2-4]. However, a major challenge to MSCs therapy is that transplanted cells undergo apoptosis, as they are exposed to an extremely harsh microenvironment in the infarcted heart. The efficiency of MSCs transplantation is limited by lower survival rate of MSCs $[5,6]$. Therefore, protection of MSCs against apoptosis is critical for successful cellular therapy. Novel strategies are being developed to maximize biologic and functional properties of MSCs, such as the preparation of cells in special bioscaffolds [7], preconditioning of cells in culture [8,9], and genetic transfection $[10,11]$.

Toll-like receptors (TLRs) are a class of molecules which play an important role in the innate immune system for the recognition of pathogen-associated molecular patterns by immune cells, initiating a primary response toward invading pathogen and recruitment of the adaptive immune response [12-14]. Recent research found that MSCs express TLR molecules 1 to 8. Pam3Cys, a prototypic ligand for TLR2, induced proliferation of MSCs and regulated their differentiation [15]. Lipopolysaccharide (LPS) is the antigenic component of the gram-negative bacterial cell wall and is known as the ligand of Toll-like receptor-4 (TLR4). In our previous study, we found that $1.0 \mu \mathrm{g} / \mathrm{ml}$ LPS could protect MSCs against apoptosis induced by oxidative stress, and enhance the proliferation of MSCs [16]. However, whether LPS could protect MSCs against apoptosis and increase the survival rate of engrafted MSCs in the infarcted myocardium need to be further investigated.

In the present study, we preconditioned MSCs with 1.0 $\mu \mathrm{g} / \mathrm{ml}$ LPS, then transplanted them into ischemic myocardium, and observed the survival and cardiac protective capacity of MSCs in a rat acute myocardial infarction model. Furthermore, we tried to explore potential mechanisms and the role of TLR4 in the signal pathway of LPSinduced cardiac protection.

\section{Methods}

\section{Animal preparation}

Adult male C57BL/10J mice (wild type, 68 weeks, $2530 \mathrm{~g}$ ) and $\mathrm{C} 57 \mathrm{BL} / 10 \mathrm{ScNJ}$ mice (TLR4 gene deleted type, 68 weeks, $2530 \mathrm{~g})$ were provided by the Model Animal Research Centre of Nanjing University (Nanjing, China). Adult female Wistar rats (210250 g) were purchased from Slac company (Shanghai, China). The procedure was performed in accordance with the "Guide for the Care and
Use of Laboratory Animals" (NIH Publication No. 85-23, National Academy Press, Washington, DC, revised 1996). The study protocol was approved by the Animal Care and Use Committee of Nanjing Medical University.

\section{Isolation, expansion and labeling of MSCs}

Wild MSCs (wMSCs) were harvested from male C57BL/ 10J mice, and TLR4 gene deleted MSCs (tMSCs) were isolated from male $\mathrm{C} 57 \mathrm{BL} / 10 \mathrm{ScNJ}$ mice, respectively. Isolation of MSCs from mice was performed as previously described with minor modifications [17]. Briefly, mice were sacrificed humanely and femurs were aseptically harvested. Whole marrow cells were obtained by flushing the bone marrow cavity with low glucose Dulbecco's Modified Eagle's Medium (L-DMEM, Hyclone, USA). Cells were centrifuged at $1000 \times g$ for 5 minutes and the supernatant was removed. The cell pellet was then re-suspended with L-DMEM supplemented with 10\% fetal bovine serum (FBS, Hyclone, USA), $100 \mathrm{U} / \mathrm{ml}$ penicillin (Invitrogen), $100 \mathrm{U} / \mathrm{ml}$ streptomycin (Invitrogen), and incubated at $37^{\circ} \mathrm{C}$ in a $5 \% \mathrm{CO}_{2}$ atmosphere. After 24 hours, non-adherent cells in suspension were discarded and culture media was replaced every three or four days thereafter. When MSCs reached $80 \% 90 \%$ of confluence, they were trypsinized by the addition of $0.25 \%$ trypsinEDTA (Sigma-Aldrich, USA), and then re-plated in culture flasks at a density of $5 \times 10^{4} / \mathrm{cm}^{2}$. Cells between passages 4 and 5 were utilized for experiment. Cells were confirmed to be MSCs by cell surface markers with flow cytometry analysis: CD 14*; CD29+; CD34; CD44+; CD45, and CD105+.

To label MSCs with 1,1'-dioctadecyl-3,3,3'3'-testramethylindo-carbocyanine perchlorate (DiI), $2 \mu \mathrm{g} / \mathrm{ml}$ DiI was added to MSCs suspension and incubated at $37^{\circ} \mathrm{C}$ for 5 minutes, then at $4^{\circ} \mathrm{C}$ for 15 minutes with occasional mixing. MSCs labeled with DiI were washed 3 times with PBS. All cells were kept frozen until use.

\section{VEGF assessment by Enzyme-link immunosorbent assay (ELISA)}

wMSCs and tMSCs were plated in 24 well plates respectively at a concentration of $1 \times 10^{5}$ cells/well $/ \mathrm{ml}$ and incubated with serum-free L-DMEM. After 24 hours, wMSCs and tMSCs were stressed with different concentrations of LPS $(0 \mu \mathrm{g} / \mathrm{ml}, 0.01 \mu \mathrm{g} / \mathrm{ml}, 0.1 \mu \mathrm{g} / \mathrm{ml}, 1.0 \mu \mathrm{g} / \mathrm{ml}, 10 \mu \mathrm{g} /$ $\mathrm{ml})$ respectively. Cells were subsequently exposed to 5 nmol/L pyrrolidine dithiocarbamate (PDTC) or not, which was an inhibitor of NF- $\kappa \mathrm{B}$. After 48 hours of incubation, supernatants were harvested. Concentration of vascular endothelial growth factor (VEGF) in supernatants was determined by VEGF ELISA kits (R\&D Systems) according to the instruction of the manufacturer. Experiments were repeated three times for verification of results. 


\section{Myocardial infarction model and MSCs transplantation} Female Wistar rats were anesthetized with ketamine (100 $\mathrm{mg} / \mathrm{kg}$ ) by intraperitoneal injection and mechanically ventilated. Under a sterile condition, the heart was exposed through a left thoracotomy, and the left anterior descending coronary artery was ligated at just below the atrioventricular border. Successful ligation was identified by cyanosis of the left ventricular anterior wall and ST-T elevation on electrocardiogram. The rats were allowed to recover under care. Before transplantation, LPS-preconditioned nMSCs and tMSCs were exposed to $1.0 \mu \mathrm{g} / \mathrm{ml} \mathrm{LPS}$ for 48 hours and collected. 80 rats were used in our experiment. 12 rats died after AMI, and 8 rats died within 7 days after AMI. One week after AMI, remaining 60 rats were divided into 4 groups randomly and given an intramyocardial injection with one of the following treatments: 30 $\mu \mathrm{l}$ PBS (control group, $\mathrm{n}=15$ ), $3 \times 10^{6} \mathrm{wMSCs} / 30 \mu \mathrm{l}$ (wMSCs group, $\mathrm{n}=15$ ), $3 \times 10^{6}$ LPS-preconditioned wMSCs/30 $\mu$ l (LPS-wMSCs group, $\mathrm{n}=15$ ), or $3 \times 10^{6}$ LPSpreconditioned tMSCs $/ 30 \mu$ l (LPS-tMSCs group, $\mathrm{n}=15$ ). $3 \times 10^{6}$ MSCs were injected into two sites of the myocardium with a bent 26-gauge needle, one within the infarct area and the other in the myocardium bordering the ischemic area. At the end of experiment, the chest was closed, and animals were weaned from the ventilator and allowed to recover. Three weeks after cells transplantation, the rats were sacrificed and hearts from different groups were harvested for the following experiments.

\section{Functional assessment by echocardiography}

Three weeks after cells transplantation, the rats were undergone cardiac function assessment by transthoracic echocardiography with $12-\mathrm{MHz}$ phased-array transducer (Hewlett Packard). The heart was imaged in the cross-sectional mode in parasternal long- and short-axis views of the left ventricle (LV). Average LV end-diastolic diameter (LVDd), LV end-systolic diameter (LVDs), LV ejection Fraction (LVEF) and LV fractional shortening (FS) were measured from three consecutive cardiac cycles. All measurements were done by two experienced echocardiographer who were blinded to treatment assignment.

\section{Fibrosis assessment by Masson's trichrome}

To detect fibrosis in cardiac muscle, the LV myocardium ( $n=5$, each) was fixed in 4\% paraformaldehyde, cut transversely, embedded in paraffin, and stained with Masson's trichrome. Ten anterolateral sections from each heart were evaluated in their entirety and quantified. Fibrosis was determined by measuring the collagen area as a proportion of the total area under observation. These morphometric studies were performed by two examiners who were blinded to treatment assignment.

\section{Evaluation of survival of engrafted MSCs}

Hearts were harvested, soaked in 30\% sucrose in PBS overnight at $4^{\circ} \mathrm{C}$ and then embedded in Tissue-Tak OCT (Sakura). Serial $20 \mu \mathrm{m}$ thick sections were cut at $-20^{\circ} \mathrm{C}$ and observed under fluorescence microscope (Leica Microsystems, Wetzlar, Germany). Engrafted MSCs were identified by the presence of DiI-labeled cells.

Because the engrafted cells were harvested from male mice, the survival rate of the transplanted MSCs could be examined by the quantitation of sry (sex-determining region of Y-chromosome) gene in the female rat heart, using real-time fluorescence TaqMan PCR 3 weeks after cells transplantation. Briefly, after the animals were killed, hearts from different groups were removed and DNA was isolated using Genomic DNA Isolation Kit (QIAGEN). Specific primers were designed based on the GeneBank sequences of the sex-determining region of the $\mathrm{Y}$ chromosome5 of the rat (sense 5'-GAGGCACAAGTTGGCTCAACA-3'; antisense 5'-CTCCTGCAAAAAGGGCCTTT-3') [18]. Quantitative PCR was performed and analyzed as described previously [19].

\section{TUNEL assay}

Three weeks after cells transplantation, apoptotic cardiomyocytes in the infarcted heart were evaluated by TUNEL assay using an in situ Cell Death Detection Kit (Roche, Germany) according to the manufacturer's instructions. Apoptotic cells were identified by brown colour in their nuclei. Tissue sections were examined microscopically and the percentage of apoptotic cells per total cells was determined in eight randomly chosen fields.

\section{Immunohistochemical assay}

Rats from each group were sacrificed 3 weeks after cells transplantation. Heart muscle samples were fixed in $4 \%$ paraformaldehyde, embedded in paraffin, and sectioned at $5 \mu \mathrm{m}$ intervals. Endothelial cells were identified by the expression of von Willebrand Factor (vWF). Immunohistology was performed with specific primary antibody against vWF (1:100, abcom). Five fields on the slide presenting infarcted area from each heart were randomly chosen for counting stained blood vessels under microscope (×100, Olympus CX-21). The blood vessel density was expressed as vessel number/field.

\section{Western blot analysis of VEGF, Akt and phospho-Akt}

Cytoplasmic protein was prepared from heart tissue and immunoblot was performed as described previously [20]. Protein was analyzed using 10\% sodium dodecyl sulphate-polyacrylamide gel electrophoresis (SDS-PAGE) and transferred to nitrocellulose membranes (Bio-Rad). Membranes were then incubated with primary antibodies including VEGF (1:1000, Cell Signaling), Akt (1:1000, Cell Signaling), phosphorylated Akt (1:1000, Cell Signal- 
ing) and $\beta$-actin (1:5000, Sigma) at $4{ }^{\circ} \mathrm{C}$ overnight respectively. The membranes were then incubated with peroxidase labeled secondary antibody (1:1000, Santa Cruz, USA) at $37^{\circ} \mathrm{C}$ for 2 hours. Signals were detected by enhanced chemiluminescence (Amersham, USA). Densitometric analysis for the blots was performed with NIH image software. Experiments were repeated 6 times for verification of results.

\section{Statistical analysis}

Data are expressed as mean \pm SEM and analysed with SPSS11.0 statistical software. Differences between groups were analyzed by Student $t$ test or Fisher's exact test, where appropriate. Statistical significance was set at $<0.05$ level.

\section{Results}

LPS promoted VEGF secretion of MSCs in vitro

VEGF concentration was higher in the groups following LPS treatment than that without it (concentration of LPS is $0,0.01,0.1,1.0,10.0 \mu \mathrm{g} / \mathrm{ml}$ and corresponding concentration of VEGF is $615.5 \pm 36.7,892.7 \pm 35.3,1163 \pm 55.8$,
$1387 \pm 48.1,938.3 \pm 35.2 \mathrm{pg} / 10^{5}$ cells $)$. VEGF concentration was the highest after incubation with $1.0 \mu \mathrm{g} / \mathrm{ml} \mathrm{LPS}$ for 48 hours (Fig 1A). In the presence of NF- $\kappa B$ inhibitorPDTC, LPS stimulation induced increase in VEGF expression was reduced $(718.3 \pm 32.7$ vs.1387 $\pm 48.1 \mathrm{pg} /$ $10^{5}$ cells, respectively, $\left.P<0.01\right)$. LPS induced stimulation of VEGF expression in tMSCs is less than that of wild MSCs $\left(760 \pm 38.2\right.$ vs. $1387 \pm 48.1 \mathrm{pg} / 10^{5}$ cells, respectively, $P<0.01$, Fig 1B).

\section{LPS-preconditioned MSCs improved cardiac function}

Three weeks after transplantation, LPS-wMSCs group had greater LVEF than wMSCs group and LPS-tMSCs group $(P$ $<0.01)$. These three groups had significantly greater LVEF than control group $(P<0.01)$, whereas without difference between wMSCs group and LPS-tMSCs group. Other echocardiographic parameters, including FS, LVDd and LVDs, showed similar difference among groups (table 1). The results suggested that an improved cardiac function was obtained by injection of LPS-pretreated wMSCs.
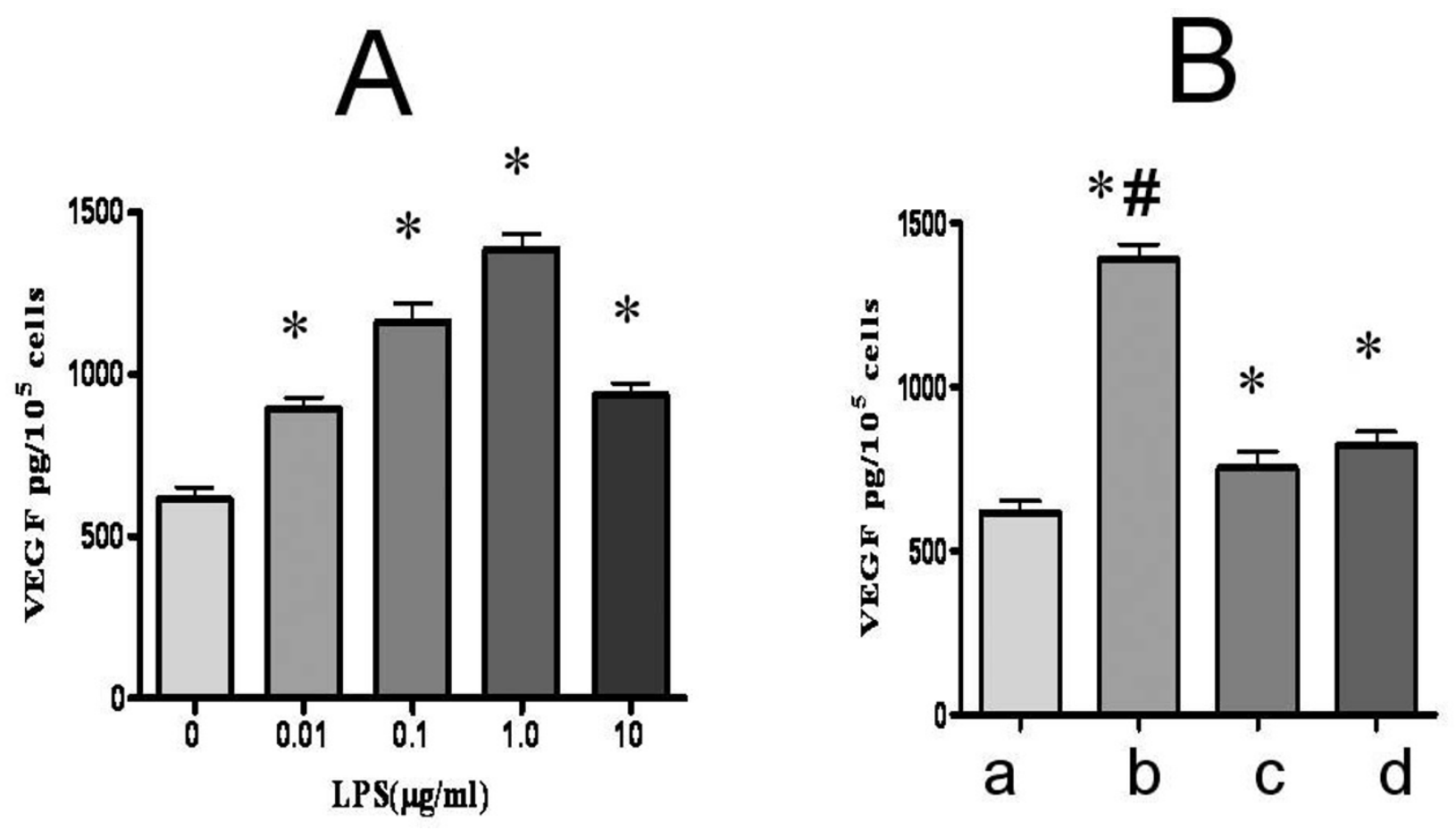

Figure I

VEGF concentration in the culture supernant of MSCs. ELISA analysis of supernatant after stimulation of LPS is shown. Wild MSCs were exposed to increasing doses of LPS for 48 hours. VEGF concentration increased after LPS treatment and VEGF concentration was the highest after incubation with $1.0 \mu \mathrm{g} / \mathrm{ml}$ LPS. B. In the presence of NF- $\kappa$ B inhibitor-PDTC, LPS stimulation caused a subsequent decrease in VEGF expression compared with that without NF- $\kappa B$ inhibition. LPS stimulation on tMSCs caused an obvious decrease in VEGF expression compared with that of wild MSCs. (a. VEGF concentration of wMSCs without stimulation of LPS; b. VEGF concentration of wMSCs with $1.0 \mu \mathrm{g} / \mathrm{ml}$ LPS stimulation; c. VEGF concentration of wMSCs with stimulation of $1.0 \mu \mathrm{g} / \mathrm{ml}$ LPS and $5 \mathrm{nmol} / \mathrm{L}$ PDTC; d. VEGF concentration of TLR4 gene deleted MSCs with stimulation of $1.0 \mu \mathrm{g} / \mathrm{ml}$ LPS) Data are mean \pm SEM. $* P<0.05$ vs. control group, $\# P<0.05$ vs. NF- $\kappa B$ inhibition and TLR4 deletion groups. 
Table I: Cardiac function 3 weeks after surgery.

\begin{tabular}{lllll}
\hline & LVDd $(\mathrm{cm})$ & $\operatorname{LVSd}(\mathrm{cm})$ & $\operatorname{LVEF}(\%)$ & FS(\%) \\
\hline control group & $0.78 \pm 0.02$ & $0.68 \pm 0.03$ & $30.66 \pm 1.56$ & $11.21 \pm 0.45$ \\
wMSCs group & $0.70 \pm 0.02^{\mathrm{a}}$ & $0.54 \pm 0.03^{\mathrm{a}}$ & $51.18 \pm 0.97^{\mathrm{a}}$ & $21.13 \pm 0.55^{\mathrm{a}}$ \\
LPS-wMSCs group & $0.68 \pm 0.02^{\mathrm{a}, \mathrm{b}, \mathrm{c}}$ & $0.46 \pm 0.02^{\mathrm{a}, \mathrm{b}, \mathrm{c}}$ & $65.43 \pm 1.25^{\mathrm{a}, \mathrm{b}, \mathrm{c}}$ & $25.88 \pm 0.54^{\mathrm{a}, \mathrm{b}, \mathrm{c}}$ \\
LPS-tMSCs group & $0.71 \pm 0.02^{\mathrm{a}}$ & $0.57 \pm 0.02^{\mathrm{a}}$ & $50.38 \pm 1.29 \mathrm{a}$ & $20.91 \pm\left. 0.7\right|^{\mathrm{a}}$ \\
\hline
\end{tabular}

Note: ${ }^{a} P<0.01$ vs. control group; ${ }^{b} P<0.01$ vs. WMSCs group; $c p<0.01$ vs. LPS-tMSCs group.

\section{LPS-preconditioned MSCs reduced the fibrosis of infarcted myocardium}

Masson's trichrome staining demonstrated modest myocardial fibrosis in the control group (11.1 $\pm 0.8 \%)$. wMSCs and LPS-preconditioned tMSCs significantly reduced fibrosis $(8.3 \pm 0.5 \%$ and $8.9 \pm 0.6 \%, P<0.05)$, whereas LPS-preconditioned wMSCs reduced fibrosis further $(6.6 \pm 0.5 \%, P<0.05)$. There was no statistical significance between wMSCs group and LPS-tMSCs group (Fig 2).

\section{Survival of transplanted cells}

Many engrafted MSCs were detected along the track of needle injection by the presence of DiI-labeled cells. After 3 weeks, a decrease in the absolute number of engrafted cells was observed in the three MSCs transplanted groups, and transplanted cells were not found in control group (Fig 3A). However, real-time PCR for sry gene showed that the survival rate of donor cells in LPS-wMSCs group was significantly higher $(1.89 \pm 0.10$-folds $)$ compared with that in wMSCs group ( 1 fold, $P<0.01$ ). The survival of the donor cells in LPS-tMSCs group was higher $(1.09 \pm 0.04$ folds) than that in wMSCs group, but did not show significant statistical difference (Fig 3B). These results indicate that LPS preconditioning can enhance the survival of engrafted MSCs in the infarcted heart.
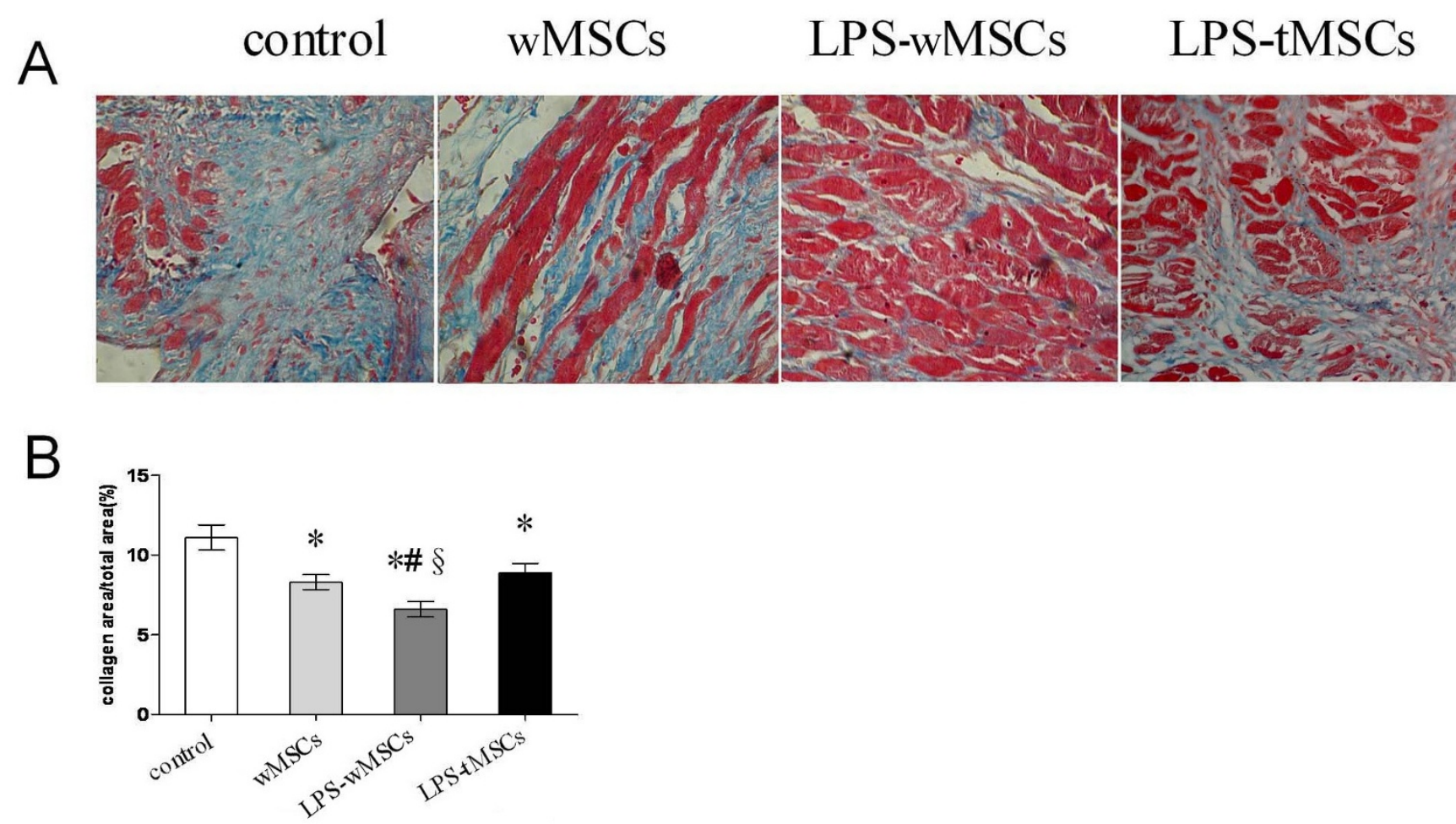

\section{Figure 2}

LPS-preconditioned MSCs reduced the fibrosis of infarcted myocardium. Representative samples of myocardial fibrosis stained with Masson's trichrome $(\times 400)$. B. Quantitative analysis of myocardial fibrosis. Data are mean \pm SEM. $* P<$ 0.05 versus control group; \#P $<0.05$ versus wMSCs group; $\$ P<0.05$ versus LPS-tMSCs group. 

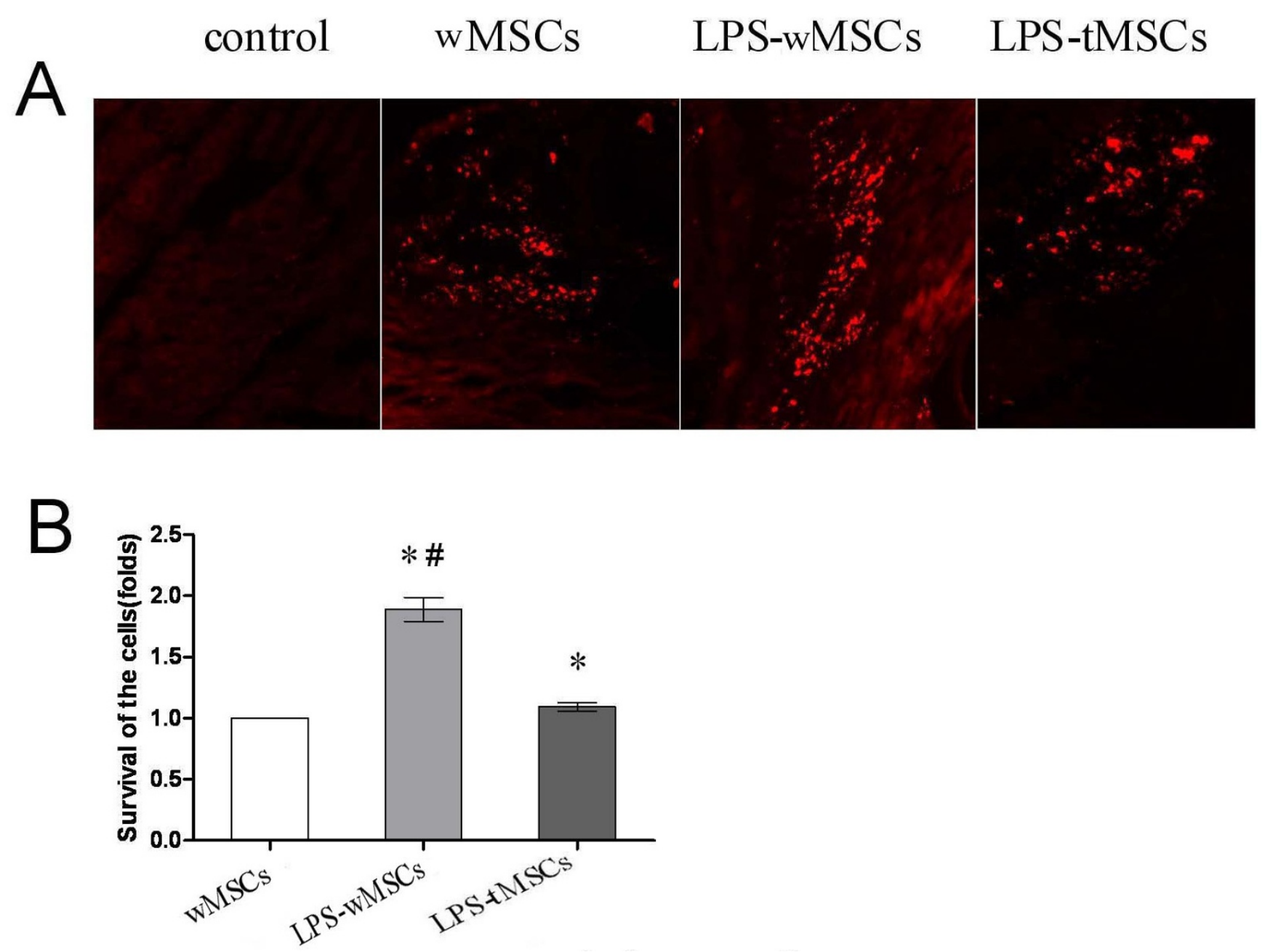

Figure 3

LPS preconditioning enhanced the survival of engrafted MSCs. A. Engrafted MSCs were detected by the presence of Dil-labeled cells (red) and cells were not found in control group $(\times 200)$. B. Real-time PCR for sry gene in the female heart tissue samples at 3 weeks after sex-mismatched cell transplantation. The fold change in sry gene expression in different groups was calculated. The result showed significantly higher survival rate of the engrafted cells in the LPS-wMSCs group compared with that in wMSCs group and LPS-tMSCs group. Data are mean \pm SEM. $* P<0.0$ I versus wMSCs group; $\# P<0.0$ I versus LPStMSCs group.

\section{LPS-preconditioned MSCs transplantation reduced the apoptosis of myocardium \\ TUNEL-positive nuclei staining was detectable in inf- arcted heart muscle cells in both control and experimental groups (Fig 4A). The percentage of TUNEL-positive cells markedly decreased in LPS-wMSCs group $(14.8 \pm 1.5 \%)$, wMSCs group $(23.4 \pm 2.1 \%)$ and LPS-tMSCs group $(23.2$ $\pm 1.6 \%)$, compared with that in control group $(34.3 \pm$ $1.7 \%, P<0.01)$. The percentage of apoptotic cells was the lowest in LPS-wMSCs group among the four groups $(P<$ 0.01) (Fig 4B).}

\section{LPS-preconditioned MSCs transplantation increased vascular density}

Immunostaining of the infarcted myocardium for vWF expression showed an augmentation of neovascularization in the cells-transplanted groups (Fig 5A). 3 weeks after cells or PBS injection, blood vessel density per fields in the infarct or peri-infarct zones was significantly greater in LPS-wMSCs group $(45.3 \pm 4.3, P<0.01)$ than that in wMSCs group $(32.2 \pm 3.1)$ and LPS-tMSCs group $(31.1 \pm$ $2.7)$. Control group $(22.8 \pm 1.9, P<0.01)$ had the lowest vessel density among the 4 groups (Fig 5B). 

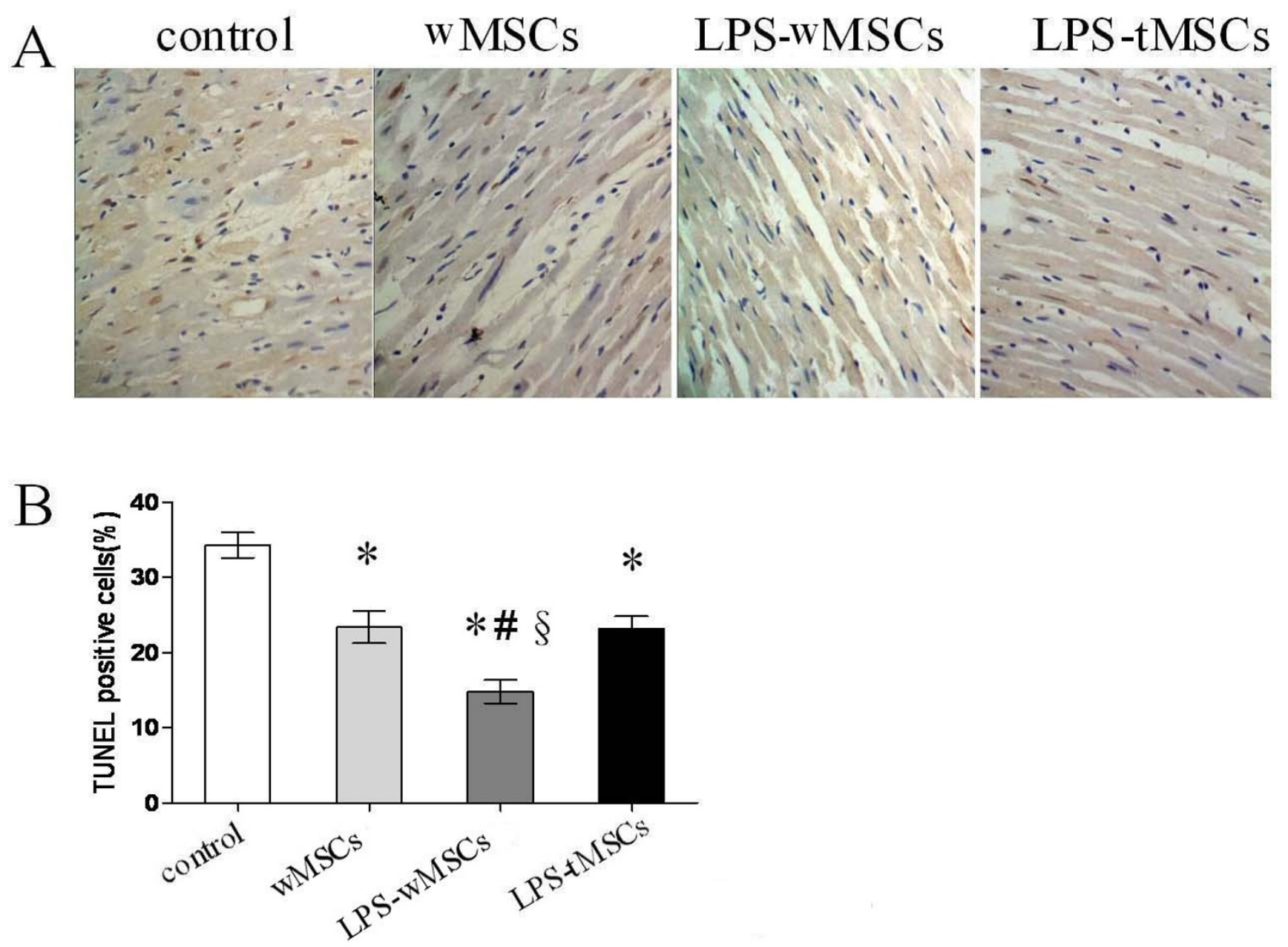

Figure 4

LPS-preconditioned MSCs transplantation reduced the apoptosis of myocardium. A. Representative photo-micrographs of TUNEL-positive nuclei staining (brown) in ischemic cardiac muscle cells $(\times 400)$. B. The percentage of apoptotic cells was the lowest in LPS-wMSCs group among the four groups. Data are mean \pm SEM. $* P<0.01$ versus control group; $\# P<0.0$ I versus wMSCs group; $\$ P<0.01$ versus LPS-tMSCs group.

\section{LPS-preconditioned MSCs transplantation increased expression of VEGF and phosphorylated Akt in vivo}

To determine if LPS preconditioning improves VEGF secretion in vivo, protein was collected from infarcted myocardium. Western blot analysis showed that levels of VEGF were increased in cells transplanted groups compared with that in control group $(P<0.05)$. LPS-wMSCs group had the highest VEGF secretion among the four groups (Fig 6A). To investigate whether LPS preconditioning could induce the activation of PI3K/Akt signalling in the myocardium, we examined the level of phospho-Akt in the myocardium. As shown in Fig 6B, significant increase in the ratio of phospho-Akt/Akt was observed in the cells-transplanted groups compared with that in control group $(P<0.05)$. The ratio of phospho-Akt/Akt was the highest in the LPS-wMSCs group among the four groups $(P<0.05)$. Thus, LPS-pretreated MSCs transplantation increased expression of VEGF and phospho-Akt in infarcted myocardium.

\section{Discussion}

The main findings of this study are 1) LPS preconditioning can improve the survival of MSCs, promote expression of VEGF and phospho-Akt in infarcted myocardium; 2) LPS-preconditioned MSCs transplantation can enhance cardiac function, reduce apoptosis of myocardium, inhibit fibrosis and elevate vascular density after MI; 3 ) TLR4 plays an important role in the signal pathway of LPS-induced cardiac protection.

Although few reports have quantified stem cell survival after transplantation, donor stem cell survival may be as 

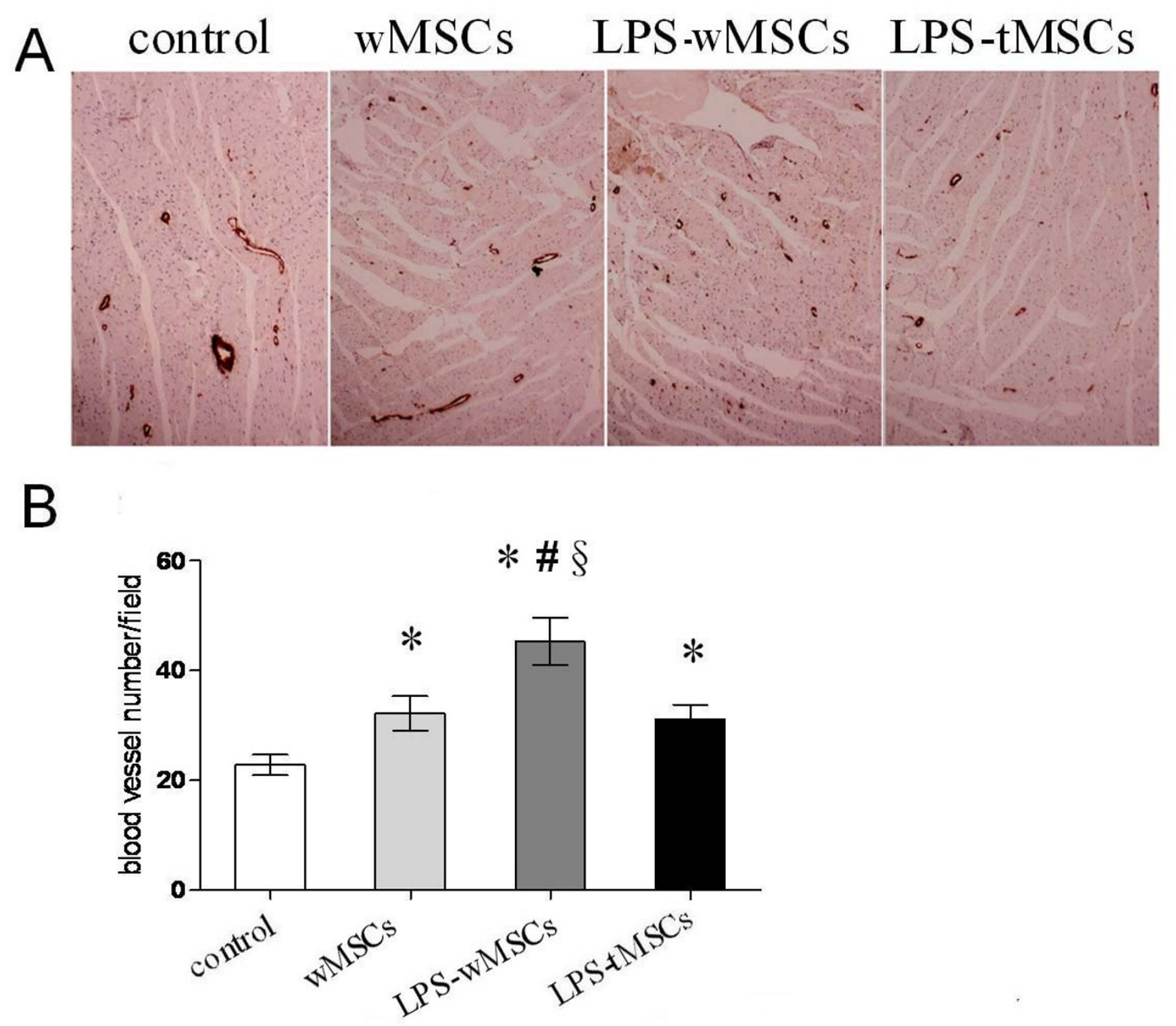

\section{Figure 5}

LPS-preconditioned MSCs transplantation increased vascular density. A. Endothelial cells were stained with antibody against vWF, and blood vessel numbers were counted $(\times 100)$. B. Five fields were randomly selected from each sample $(n=8)$, and blood vessel density is shown as the vessel number/field. Data are mean \pm SEM. $* P<0.0$ I vs. control group; $\# P<0.01$ vs. wMSCs group; $\$ P<0.01$ vs. LPS-tMSCs group.

low as $1 \% 5 \% 48$ hours after transplantation $[2,6]$, possibly due to a hostile, nutrient-deficient, inflammatory environment within damaged myocardium. This low survival may limit the sustained reparative capacity of stem cells in vivo. Enhanced survival of transplanted stem cells may increase their cytoprotective efficacy. Our previous study had suggested that $1.0 \mu \mathrm{g} / \mathrm{ml}$ LPS could protect MSCs from oxidative stress-induced apoptosis and improve the survival of MSCs via TLR4 and PI3K/Akt pathway. After pretreated by $1.0 \mu \mathrm{g} / \mathrm{ml}$ LPS, MSCs strengthened the power against oxidative stress and inflammatory environment in infarcted area. In present study, we also found that survival ratio of transplanted MSCs was elevated in infarcted myocardium after LPS preconditioning by detecting the sry gene in the donor heart.

Recent studies have indicated that paracrine mechanism, carried out by the cells through the release of soluble cel- 

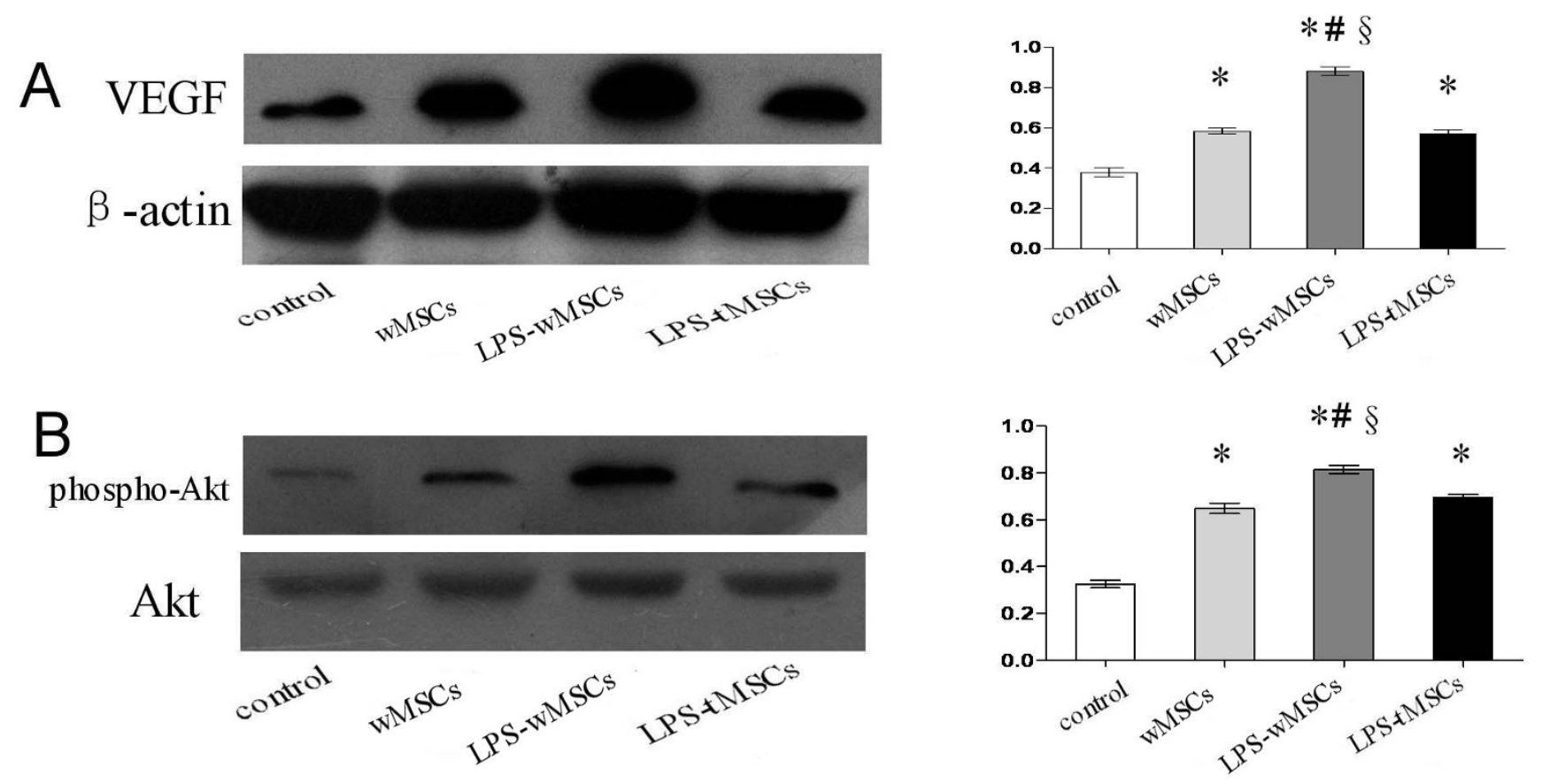

Figure 6

LPS-preconditioned MSCs transplantation increased expression of VEGF and phosphorylated Akt protein in vivo. Representative Western blots for expression of VEGF. Corresponding $\beta$-actin blots are shown as a control for sample loading. Bar graph on right shows quantitation. The protein levels for each sample were determined as a ratio to their corresponding $\beta$-actin levels. B. Representative Western blots for expression of phospho-Akt, Akt. Total Akt served as a loading control. Bar graph on right shows quantitation. The protein levels of phospho-Akt for each sample were determined as a ratio to their corresponding Akt levels. Data are mean \pm SEM. $* P<0.05$ versus control group; \# $>0.05$ versus wMSCs group; $\$ P<$ 0.05 versus LPS-tMSCs group.

lular factors, might be a critical mechanism of tissue repair and functional improvement after MSCs transplantation [21]. VEGF is a crucial paracrine factor in MSCs-mediated cardioprotection. In addition to its potent angiogenic function, VEGF can stimulate proliferation, delay senescence, suppress apoptosis and promote survival of various cells $[22,23]$. It has reported that MSCs exposed to LPS could increase expression of VEGF [24,25]. In in vitro study, we demonstrated that a significant level of VEGF was detected in the culture medium of LPS-treated MSCs. In in vivo study, Western bolt analysis also implied that LPS-preconditioning MSCs transplantation released more VEGF in infarcted myocardium than that without LPS preconditioning. As a result of VEGF secretion, the vascular density was increased in LPS-preconditioning group than that without LPS-preconditioning. Furthermore, the protected cardiac function and the reduced apoptosis of myocardium in infarcted heart were also related with expression of VEGF. Thus, we demonstrated that LPS-preconditioning promoted the release of VEGF, which in turn improved the effect of MSCs transplantation in the infarcted area.
Phosphoinositide 3-kinase (PI3K) and its downstream target serine/threonine kinase Akt are now recognized as one of the most critical pathways in regulating cellular activation, inflammatory responses and apoptosis $[26,27]$. Activation of PI3K/Akt-dependent signalling has been shown to prevent cardiac myocyte apoptosis and protect the myocardium from AMI $[10,28]$. Akt is activated by site-specific phosphorylation. In our study, we found that the level of phosphor-Akt was elevated and the apoptosis of myocardium was reduced in LPS-wMSCs group compared with that in wMSCs group. So we demonstrated that LPS-preconditioned MSCs resulted in significantly increased levels of phospho-Akt in the myocardium which positively correlated with cardioprotection. Our results indicated that effect of LPS-conditioned MSCs transplantation was mediated partially through a PI3K/Akt-dependent mechanism.

TLRs are a conservative family of receptors that recognize pathogen-associated molecular patterns and promote the activation of immune cells [29,30]. Recent studies have shown that the heart expresses TLR 4 mRNA and protein [31], and TLR4 plays a role in myocardial dysfunction 
during bacterial sepsis [32,33]. However, a low dose of LPS $(0.2 \mathrm{mg} / \mathrm{kg})$ preconditioning induced cardioprotection in a rodent model of ischaemia/reperfusion injury [34]. Preconditioning, injury-induced protection from subsequent injury, has been proven to be a powerful form of cardioprotection. Jiang et al. [35] preconditioned MSCs with hypoxia, transplanted the stem cells into ischemic myocardium, and observed enhanced survival and cytoprotective capacity. Guo et al. [36] preconditioned MSCs with IGF-1 and found enhancement of the number of MSCs attracted into the infarcted heart. In the present study, we found LPS-preconditioning could enhance survival of MSCs, stimulate expression of VEGF and activate PI3K/Akt pathway. Conversely, TLR4-deleted MSCs (tMSCs) released less VEGF and exerted less functions in reducing apoptosis of myocardium than LPS-preconditioning wMSCs. TLR-mediated signalling activates NF- $\kappa$, which plays a critical role in regulating expression of genes, such as VEGF. In our in vitro study, we found that NF- $\kappa \mathrm{B}$ inhibition prevented secretion of VEGF under the LPS condition. So we concluded that TLR4/NF- $\kappa B$ signalling pathway played an important role in cardioprotection performed by LPS preconditioning. LPS preconditioning could promote expression of other cytokines, such as fibroblast growth factor 2 (FGF2), insulin-like growth factor 1 (IGF-1), and hepatocyte growth factor (HGF) [25]. The exact effects of these cytokines in infarcted heart need a further investigation.

In conclusion, this study demonstrates that LPS preconditioning can enhance survival of MSCs, stimulate expression of VEGF, and activate PI3K/Akt pathway. LPS preconditioning before MSCs transplantation leads to superior therapeutic neovascularization and recovery of cardiac function. Therefore, LPS preconditioning provides a novel strategy in maximizing biologic and functional properties of MSCs.

\section{Competing interests}

The authors declare that they have no competing interests.

\section{Authors' contributions}

YY carried out the main experiment and drafted the manuscript. FZ conceived of the study, designed the experiment and helped to drafted the manuscript. LW performed immunohistochemical assay. GZ finished statistical analysis. ZW participated in Western blot analysis. JC carried out culture of MSCs and helped to finish animal model. XG provided and cultured TLR4 deleted MSCs and helped to perform the real-time PCR. All authors read and approved the final manuscript.

\section{Acknowledgements}

Project was supported by grants from the Natural Science Foundation of Jiangsu Province (No BK2007254), Ministry of Personnel of China for returned student (No DG2 16D502I) and the National Natural Science Foundation of China (No 30871078).

\section{References}

I. Price MJ, Chou CC, Frantzen M, Miyamoto T, Kar S, Lee S, Shah PK, Martin BJ, Lill M, Forrester JS, Chen PS, Makkar RR: Intravenous mesenchymal stem cell therapy early after reperfused acute myocardial infarction improves left ventricular function and alters electrophysiologic properties. Int J Cardiol 2006, II I:23I-239.

2. Toma C, Pittenger MF, Cahill KS, Byrne BJ, Kessler PD: Human mesenchymal stem cells differentiate to a cardiomyocyte phenotype in the adult murine heart. Circulation 2002, 105:93-98.

3. Amado LC, Saliaris AP, Schuleri KH, St John M, Xie JS, Cattaneo S, Durand DJ, Fitton T, Kuang JQ, Stewart G, Lehrke S, Baumgartner WW, Martin BJ, Heldman AW, Hare JM: Cardiac repair with intramyocardial injection of allogeneic mesenchymal stem cells after myocardial infarction. Proc Natl Acad Sci USA 2005, 102: I |474-1| 1479.

4. Valina C, Pinkernell K, Song YH, Bai X, Sadat S, Campeau RJ, Le Jemtel TH, Alt E: Intracoronary administration of autologous adipose tissue-derived stem cells improves left ventricular function, perfusion, and remodelling after acute myocardial infarction. Eur Heart J 2007, 28:2667-2677.

5. Geng YJ: Molecular mechanisms for cardiovascular stem cell apoptosisand growth in the hearts with atherosclerotic coronary disease and ischemic heart failure. Ann N Y Acad Sci 2003, 1010:687-697.

6. Müller-Ehmsen J, Krausgrill B, Burst V, Schenk K, Neisen UC, Fries JW, Fleischmann BK, Hescheler J, Schwinger RH: Effective engraftment but poor mid-term persistence of mononuclear and mesenchymal bone marrow cells in acute and chronic rat myocardial infarction. J Mol Cell Cardiol 2006, 41:876-884.

7. Davis ME, Hsieh PC, Grodzinsky AJ, Lee RT: Custom design of the cardiac microenvironment with biomaterials. Circ Res 2005, 97:8-15.

8. Pasha Z, Wang Y, Sheikh R, Zhang D, Zhao T, Ashraf M: Preconditioning enhances cell survival and differentiation of stem cells during transplantation in infarcted myocardium. Cardiovasc $\operatorname{Res} 2008,77:$ : 34- I 42.

9. Kubo M, Li TS, Suzuki R, Ohshima M, Qin SL, Hamano K: Shortterm pretreatment with low-dose hydrogen peroxide enhances the efficacy of bone marrow cells for therapeutic angiogenesis. Am J Physiol Heart Circ Physiol 2007, 292:H2582-2588.

10. Mangi AA, Noiseux N, Kong D, He H, Rezvani M, Ingwall JS, Dzau V]: Mesenchymal stem cells modified with Akt prevent remodeling and restore performance of infarcted hearts. Nat Med 2003, 9:1195-1201.

II. Iwase T, Nagaya N, Fujii T, Itoh T, Murakami S, Matsumoto T, Kangawa K, Kitamura $S$ : Comparison of angiogenic potency between mesenchymal stem cells and mononuclear cells in a rat model of hindlimb ischemia. Cardiovasc Res 2005, 66:543-551.

12. Hoebe $K$, Janssen $E$, Beutler B: The interface between innate and adaptive immunity. Nat Immunol 2004, 5:97I-974.

13. Takeuchi O, Hoshino K, Kawai T, Sanjo H, Takada H, Ogawa T, Takeda K, Akira S: Differential roles of TLR2 and TLR4 in recognition of gram-negative and gram-positive bacterial cell wall components. Immunity 1999, I I:443-45I.

14. O'Neill LA: Therapeutic targeting of Toll-like receptors for inflammatory and infectious diseases. Curr Opin Pharmacol 2003, 3:396-403.

15. Pevsner-Fischer M, Morad V, Cohen-Sfady M, Rousso-Noori L, ZaninZhorov A, Cohen S, Cohen IR, Zipori D: Toll-like receptors and their ligands control mesenchymal stem cell functions. Blood 2007, 109:1422-1432.

16. Wang ZJ, Zhang FM, Wang LS, Yao YW, Zhao Q, Gao X: Lipopolysaccharides can protect mesenchymal stem cells from oxidative stress-induced apoptosis and enhance proliferation of MSCs via Toll-like receptor(TLR)-4 and PI3K/Akt. Cell Biol Int 2009, 33:665-674.

17. Xu M, Wani M, Dai YS, Wang J, Yan M, Ayub A, Ashraf M: Differentiation of bone marrow stromal cells into the cardiac pheno- 
type requires intercellular communication with myocytes. Circulation 2004, I 1 0:2658-2665.

18. Yau TM, Kim C, Li G, Zhang Y, Weisel RD, Li RK: Maximizing ventricular function with multimodal cell-based gene therapy. Circulation 2005, I I 2:I | 23-128.

19. Shujia J, Haider HK, Idris NM, Lu G, Ashraf M: Stable therapeutic effects of mesenchymal stem cell-based multiple gene delivery for cardiac repair. Cardiovasc Res 2008, 77:525-533.

20. Hu Z, Zhang F, Yang Z, Yang N, Zhang D, Zhang J, Cao K: Combination of simvastatin administration and EPC transplantation enhances angiogenesis and protects against apoptosis for hindlimb ischemia. J Biomed Sci 2008, 15:509-5I7.

21. Gnecchi M, He H, Noiseux N, Liang OD, Zhang L, Morello F, Mu H, Melo LG, Pratt RE, Ingwall JS, Dzau VJ: Evidence supporting paracrine hypothesis for Akt-modified mesenchymal stem cellmediated cardiac protection and functional improvement. FASEB J 2006, 20:661-669.

22. Pickkers P, Sprong T, Eijk L, Hoeven H, Smits P, Deuren M: Vascular endothelial growth factor is increased during the first $\mathbf{4 8}$ hours of human septic shock and correlates with vascular permeability. Shock 2005, 24:508-5I2.

23. Ferrara N, Gerber HP, LeCouter J: The biology of VEGF and its receptors. Nat Med 2003, 9:669-676.

24. Novotny NM, Markel TA, Crisostomo PR, Meldrum DR: Differential IL-6 and VEGF secretion in adult and neonatal mesenchymal stem cells: role of NF-KB. Cytokine 2008, 43:2 I5-219.

25. Crisostomo PR, Wang Y, Markel TA, Wang M, Lahm T, Meldrum DR: Human mesenchymal stem cells stimulated by TNF-alpha, LPS, or hypoxia produce growth factors by an NF kappa Bbut not JNK-dependent mechanism. Am J Physiol Cell Physiol 2008, 294:c675-82.

26. Dimmeler $S$, Zeiher AM: Akt takes center stage in angiogenesis signaling. Cric Res 2000, 86:4-5.

27. Brazil DP, Hemmings BA: Ten years of protein kinase $B$ signalling: a hard Akt to follow. Trends Biochem Sci 200I, 26:657-664.

28. Lim SY, Kim YS, Ahn Y, Jeong MH, Hong MH, Joo SY, Nam KI, Cho JG, Kang PM, Park JC: The effects of mesenchymal stem cells transduced with Akt in a porcine myocardial infarction model. Cardiovasc Res 2006, 70:530-542.

29. Lemaitre B, Nicolas E, Michaut L, Reichhart JM, Hoffmann JA: The dorsoventral regulatory gene cassette spätzle/Toll/cactus controls the potent antifungal response in Drosophila adults. Cell 1996, 86:973-983.

30. Medzhitov R, Preston-Hurlburt P, Janeway CA Jr: A human homologue of the Drosophila Toll protein signals activation of adaptive immunity. Nature 1997, 388:394-397.

31. Frantz S, Kobzik L, Kim YD, Fukazawa R, Medzhitov R, Lee RT, Kelly RA: Toll4 (TLR4) expression in cardiac myocytes in normal and failing myocardium. J Clin Invest 1999, 104:27I-280.

32. Nemoto S, Vallejo JG, Knuefermann P, Misra A, Defreitas G, Carabello BA, Mann DL: Escherichia coli LPS-induced LV dysfunction: role of toll-like receptor-4 in the adult heart. Am J Physiol Heart Circ Physiol 2002, 282:H23 16-2323.

33. Baumgarten $G$, Knuefermann $P$, Schuhmacher $G$, Vervölgyi $V$, von Rappard J, Dreiner U, Fink K, Djoufack C, Hoeft A, Grohé C, Knowlton AA, Meyer R: Toll-like receptor 4, nitric oxide, and myocardial depression in endotoxemia. Shock 2006, 25:43-49.

34. Ha T, Hua F, Liu X, Ma J, McMullen JR, Shioi T, Izumo S, Kelley J, Gao X, Browder W, Williams DL, Kao RL, Li C: Lipopolysaccharideinduced myocardial protection against ischaemia/reperfusion injury is mediated through a PI3K/Akt-dependent mechanism. Cardiovasc Res 2008, 78:546-553.

35. Jiang S, Haider HKh, Idris NM, Salim A, Ashraf M: Supportive interaction between cell survival signaling and angiocompetent factors enhances donor cell survival and promotes angiomyogenesis for cardiac repair. Circ Res 2006, 99:776-784.

36. Guo J, Lin G, Bao C, Hu Z, Chu H, Hu M: Insulin-like growth factor I improves the efficacy of mesenchymal stem cells transplantation in a rat model of myocardial infarction. J Biomed Sci 2008, I 5:89-97.

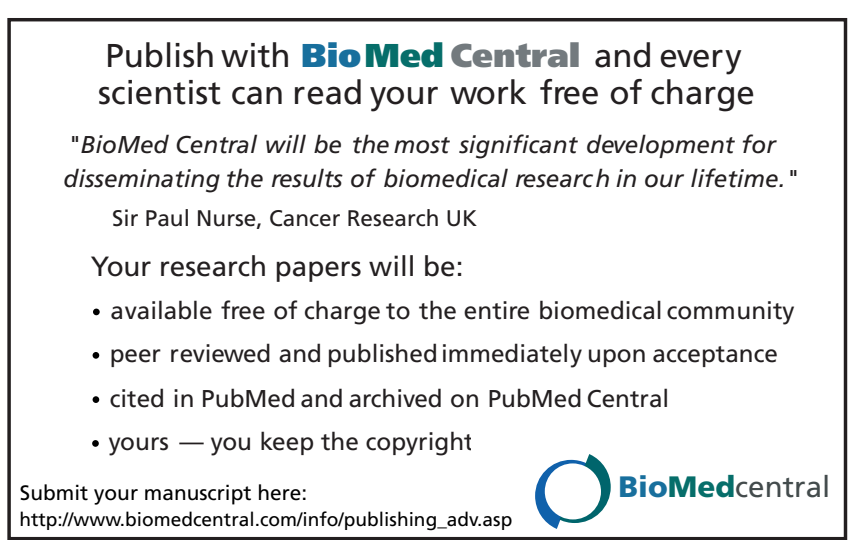

